\title{
Pulmonary endarterectomy normalizes interventricular dyssynchrony and right ventricular systolic wall stress
}

\author{
Gert-Jan Mauritz', Anton Vonk-Noordegraaf', Taco Kind', Sulaiman Surie ${ }^{1}$, Jaap J Kloek ${ }^{5}$, Paul Bresser ${ }^{6}$,
} Nabil Saouti ${ }^{1}$, Joachim Bosboom¹, Nico Westerhof ${ }^{1,3}$ and J Tim Marcus ${ }^{2 *}$

\begin{abstract}
Background: Interventricular mechanical dyssynchrony is a characteristic of pulmonary hypertension. We studied the role of right ventricular (RV) wall stress in the recovery of interventricular dyssynchrony, after pulmonary endarterectomy (PEA) in chronic thromboembolic pulmonary hypertension (CTEPH).

Methods: In 13 consecutive patients with CTEPH, before and 6 months after pulmonary endarterectomy, cardiovascular magnetic resonance myocardial tagging was applied. For the left ventricular (LV) and RV free walls, the time to peak (Tpeak) of circumferential shortening (strain) was calculated. Pulmonary Artery Pressure (PAP) was measured by right heart catheterization within 48 hours of PEA. Then the RV free wall systolic wall stress was calculated by the Laplace law.

Results: After PEA, the left to right free wall delay (L-R delay) in Tpeak strain decreased from $97 \pm 49 \mathrm{~ms}$ to $-4 \pm$ $51 \mathrm{~ms}(P<0.001)$, which was not different from normal reference values of $-35 \pm 10 \mathrm{~ms}(P=0.18)$. The RV wall stress decreased significantly from $15.2 \pm 6.4 \mathrm{kPa}$ to $5.7 \pm 3.4 \mathrm{kPa}(P<0.001)$, which was not different from normal reference values of $5.3 \pm 1.39 \mathrm{kPa}(P=0.78)$. The reduction of $\mathrm{L}-\mathrm{R}$ delay in Tpeak was more strongly associated with the reduction in RV wall stress $(r=0.69, P=0.007)$ than with the reduction in systolic PAP $(r=0.53, P=0.07)$. The reduction of L-R delay in Tpeak was not associated with estimates of the reduction in RV radius $(r=0.37, P=$ 0.21) or increase in RV systolic wall thickness ( $r=0.19, P=0.53)$.
\end{abstract}

Conclusion: After PEA for CTEPH, the RV and LV peak strains are resynchronized. The reduction in systolic RV wall stress plays a key role in this resynchronization.

Keywords: Chronic Thrombo-Embolic Pulmonary Hypertension, Pulmonary Endarterectomy, interventricular mechanical asynchrony, myocardial strain, wall stress

\section{Background}

Interventricular mechanical dyssynchrony is a characteristic of right ventricular (RV) pressure overload [1-3]. It occurs at the end of RV myocardial shortening, when the RV free wall continues shortening while the left ventricular (LV) wall is already in its early diastolic phase [4-7]. Consequently, the ventricular septum bows to the left, and the RV shortens without ejection thereby making the RV very inefficient [8], and in addition impairing

\footnotetext{
* Correspondence: jt.marcus@vumc.nl

${ }^{2}$ Department of Physics and Medical Technology, University of Amsterdam, Amsterdam, The Netherlands

Full list of author information is available at the end of the article
}

early LV filling $[9,10]$. The underlying mechanism of this prolonged RV contraction duration is unknown. In an isolated Langendorf-perfused heart, Handoko et al [11] created a L-R dyssynchrony in peak pressure by increasing RV pressure using inflation of a balloon. Two earlier studies have found a relation between L-R dyssynchrony and wall stress $[5,12]$. Since wall stress is the combined effect of pressure, volume and wall thickness, the questions remains whether dyssynchrony is best explained by RV pressure or the combination of the variables as expressed by wall stress. This insight is relevant for a better understanding of the adaptation

\section{() Biomed Central}


mechanisms of RV structure in the presence of right ventricular overload.

The aim of the present study is twofold. First to assess the effect of RV unloading on dyssynchrony in Chronic Thrombo-Embolic Pulmonary Hypertension (CTEPH). Secondly, to separate the effects on dyssynchrony induced by pressure, volume, wall thickness and wall stress. We assessed these effects on L-R dyssynchrony in CTEPH patients, before and after pulmonary endarterectomy.

\section{Methods}

\section{Patients population}

Thirteen of 17 consecutive patients with surgically accessible CTEPH, referred to the Academic Medical Center of the University of Amsterdam, were prospectively studied before and after pulmonary endarterectomy (PEA). One patient refused to participate because of claustrophobia, 1 patient died postoperatively, and 2 patients refused to undergo a second cardiovascular magnetic resonance (CMR) after surgery. Diagnosis of CTEPH and eligibility for PEA were established on the basis of previously reported procedures and criteria [13]. Diagnosis and cardiopulmonary hemodynamics were determined by pulmonary angiography and right heart catheterization. Coronary angiography was routinely performed in all patients older than 50 years of age, and in patients older than 40 years of age if they had a history of smoking.

In addition, eight healthy subjects (called 'control') were included (age $55 \pm 6$ years, 3 women), with normal electrocardiogram (ECG) and QRS width of $80 \pm 12 \mathrm{~ms}$, where RV and LV wall strains were obtained and compared with the CTEPH group. For the estimation of normal RV wall stress, we included also 8 patients (called 'normal right-sided pressure group') suspected of having PH (age $59 \pm 11$ years, 5 women) but with normal right-sided pressures confirmed by right heart catheterisation. All patients and controls gave informed consent to the study protocol, which was approved by the institutional review board of the VU University Medical Center.

\section{Right heart catheterization}

All patients underwent right heart catheterization within $48 \mathrm{~h}$ of their pre-operative CMR. Right heart catheterisation gave right atrial pressure, pulmonary artery pressure (PAP), pulmonary capillary wedge pressure (PCWP), and cardiac output (thermodilution). Pulmonary vascular resistance (PVR) was calculated as: PVR = 80 . (mean PAP-mean PCWP)/cardiac output. Postoperative hemodynamic measurements were repeated on the first or second day following PEA, before removal of the Swan-Ganz catheter (Edwards LifeSciences, Irvine, CA, USA)

\section{CMR Imaging acquisition}

All patients underwent CMR myocardial tagging at baseline before, and at least 6 months after endarterectomy. A 1.5 Siemens 'Avanto' whole body MRI system, equipped with a 6-element phased-array coil was used (Siemens Medical Solutions, Erlangen, Germany). CMR myocardial tagging with high temporal resolution (29 ms) was applied with Complementary Spatial Modulation of Magnetization (7 $\mathrm{mm}$ tag distance) and steady state free precession imaging. Parameters: Eight phaseencoding lines per heart beat, TR $3.6 \mathrm{~ms}$, TE $1.8 \mathrm{~ms}$, flip angle $20 \mathrm{deg}$, voxel size $1.2 \times 3.8 \times 6.0 \mathrm{~mm} 3$. In all patients and control subjects this tagging cine was acquired in the mid-ventricular short-axis plane. After the tagging acquisitions, the LV and RV were covered by a stack of short-axis cine CMR images for volumetric assessment, using steady state free precession imaging with a temporal resolution between 25 and $35 \mathrm{~ms}$.

\section{CMR Image analysis}

End-diastolic volume (EDV), end-systolic volume (ESV), ejection fraction and myocardial mass were calculated using MR Analytical Software System (Medis, Leiden, The Netherlands). In order to assess LV peak filling rate (PFR), LV volumes throughout the cardiac cycle were calculated.

The tagged images were analyzed with the Harmonic Phase procedure [14]. Circumferential shortening was calculated over time during the cardiac cycle. For the LV free wall, septum, and RV free wall, the peak time (Tpeak) of circumferential shortening was calculated related to the ECG R-wave by automated routines [15].

\section{LV free wall, RV free wall, and septum definitions}

The LV free wall was subdivided in 5 equal segments. The 2 segments of the LV wall that were in direct continuity with the septum were not included as part of the LV free wall. The RV free wall was delineated in the same way. The complete septum was taken for the calculation of the septal strain, from the anterior until the posterior connections with the ventricular wall. For the LV free wall, RV free wall, and septum, the strains and strain timing parameters were derived.

\section{RV End-Systolic Wall Stress}

Our estimation of RV end-systolic (ES) wall stress for both the patients and control subjects starts from the law of Laplace [16]: $R V$ end - systolic wall stress $=\frac{0.5 \times \mathrm{RV} \text { systolic pressure } \times \mathrm{RV} \text { end-systolic radius }}{\mathrm{RV} \text { end-systolic wall thickness }}$ 
The systolic RV pressure is estimated by the systolic PAP. The RV ES radius of curvature is difficult to measure directly because of the RV's irregular shape. Therefore, we estimate this radius from the RVESV by assuming that this volume can be described by a sphere in both the patients and controls. Then the RV ES radius is:

$$
\text { End }- \text { systolic radius }=0.620 \times(\mathrm{RVESV})^{1 / 3}
$$

The RV ES wall thickness is estimated by dividing the RV free wall ES volume by the RV free wall ES surface area. The RV free wall ES volume is obtained by contouring the RV free wall on every short-axis ES slice, and then applying Simpson's rule. The total RV ES surface area was calculated as: $4 \cdot \pi \cdot$ radius $^{2}$, with radius from the above equation. The RV free wall fraction of total RV surface is estimated as $2 / 3$ part. Thus the RV free wall ES surface area is calculated as $2 / 3$ times the total RV ES surface area.

\section{Statistics}

GraphPad Prism version 4.0 (GraphPad Software, San Diego, California) was used for statistical calculations. All data was tested for normal distribution. We performed a 2-tailed paired Student $t$ test to compare preand postoperative CMR measurements and hemodynamic measurements. The relations between the L-R delay in $\mathrm{T}_{\text {peak }}$ versus $\mathrm{LV}$ stroke volume, LV PFR, six minute walking distance and RV wall stress were tested by linear regression. All data are described as mean \pm standard deviation. A p value of $<0.05$ was considered statistically significant

\section{Results}

\section{Patients Characteristics}

Patient characteristics are shown in Table 1 . The median age of the patient population was 63 years (range 45-83) and 46\% were female. The ECG-QRS width before PEA was $96 \pm 9 \mathrm{~ms}$. On the basis of ECG morphology, right bundle branch block was present in 1 patient. Coronary artery disease was not present in any of the patients studied. PEA was successful in all patients, resulting in a significant reduction in mean PAP $(45 \pm 12$ vs $25 \pm 6 \mathrm{mmHg} ; P<0.001)$ and TPR $\left(870 \pm 391\right.$ vs $\left.406 \pm 171 \mathrm{dyn} \cdot \mathrm{s} / \mathrm{cm}^{5} ; P<0.001\right)$. Invasive hemodynamic measurements are summarized in Table 2. The six-minute walk distance increased from $409 \pm$ $109 \mathrm{~m}$ to $510 \pm 91 \mathrm{~m}(P<0.001)$.

\section{CMR-derived ventricular volumes and function}

As shown in Table 3, after PEA, there was a significant reduction in RVEDV and RVESV at 6 months after PEA. RV stroke volume tended to increase and RVEF increased. The preoperative hypertrophy of the RV decreased after PEA. Left ventricular EDV increased significantly with a stable LVESV. Therefore LV stroke volume improved significantly. In addition, LV peak filling rate (PFR) as corrected for LV-EDV increased significantly.

\section{Images and strains}

Figure 1 shows short-axis cine images and short-axis tagged images at the time of RV peak strain before and after PEA. Figure 2 shows an example of the circumferential shortening curves during the cardiac cycle for the

Table 1 Patients Characteristics before PEA

\begin{tabular}{|c|c|c|c|c|c|c|c|c|c|c|}
\hline Patient & Sex & $\begin{array}{c}\text { Age } \\
\text { (years) }\end{array}$ & $\begin{array}{l}\text { HR (beats/ } \\
\text { min) }\end{array}$ & $\begin{array}{c}\text { BP s/d } \\
(\mathrm{mmHg})\end{array}$ & $\begin{array}{c}\text { PAP s/d/m } \\
(\mathrm{mmHg})\end{array}$ & $\begin{array}{c}\text { PCWP } \\
(\mathrm{mmHg})\end{array}$ & $\begin{array}{c}\mathrm{CO}(\mathrm{I} / \\
\mathrm{min})\end{array}$ & $\begin{array}{l}\text { QRS Width } \\
\text { (ms) }\end{array}$ & NYHA & Medication \\
\hline 1 & $\mathrm{~m}$ & 78 & 74 & $120 / 70$ & $80 / 30 / 47$ & 5 & 3.7 & 104 & 3 & ERA \\
\hline 2 & f & 50 & 74 & $120 / 80$ & $110 / 30 / 56$ & 13 & 2.7 & 108 & 3 & none \\
\hline 3 & f & 58 & 75 & $115 / 75$ & $83 / 37 / 54$ & 14 & 3.6 & 108 & 3 & ERA \\
\hline 4 & $f$ & 43 & 72 & $120 / 80$ & $78 / 24 / 45$ & 15 & 4.2 & 88 & 3 & ERA \\
\hline 5 & $\mathrm{~m}$ & 66 & 49 & $150 / 85$ & $55 / 14 / 29$ & 11 & 5.8 & 92 & 2 & ERA \\
\hline 6 & $\mathrm{~m}$ & 69 & 75 & $130 / 80$ & $42 / 14 / 26$ & 9 & 5.9 & 94 & 2 & ERA \\
\hline 7 & $\mathrm{~F}$ & 68 & 88 & $110 / 70$ & 109/33/58 & 5 & 2.3 & 88 & 4 & ERA \\
\hline 8 & $f$ & 61 & 87 & $95 / 65$ & $78 / 33 / 50$ & 6 & 5.5 & 92 & 3 & ERA \\
\hline 9 & $\mathrm{~m}$ & 51 & 78 & $175 / 85$ & $72 / 29 / 45$ & 8 & 4.8 & 108 & 3 & ERA \\
\hline 10 & f & 60 & 69 & $131 / 90$ & $60 / 47 / 53$ & 12 & 4.0 & 82 & 3 & ERA \\
\hline 11 & f & 51 & 76 & $120 / 75$ & $48 / 17 / 26$ & 10 & 3.7 & 86 & 3 & ERA \\
\hline 12 & $\mathrm{~m}$ & 74 & 80 & $160 / 90$ & $70 / 49 / 59$ & 13 & 3.7 & 102 & 3 & ERA \\
\hline 13 & $\mathrm{~m}$ & 55 & 79 & $130 / 80$ & $55 / 18 / 32$ & 12 & 5.2 & 96 & 2 & ERA \\
\hline
\end{tabular}

$\mathrm{BP}=$ blood pressure; $\mathrm{CO}=$ cardiac output; $\mathrm{CTEPH}=$ Chronic Thrombo-Embolic Pulmonary Hypertension; $\mathrm{ERA}=$ endothelin receptor antagonist; HR = heart rate; inc. = incomplete; NYHA = New York Heart Association; PAP = pulmonary arterial pressure; PCWP = pulmonary capillary wedge pressure; RBBB = right bundle branch block; s/d/m = systolic/diastolic/mean. 
Table 2 Invasive Hemodynamic data pre and post PEA

\begin{tabular}{|c|c|c|c|}
\hline Parameter & Pre PEA & Post PEA ICU & $p$-Value \\
\hline Heart Rate & $75 \pm 10$ & $74 \pm 8$ & ns \\
\hline PAPsystolic (mm Hg) & $72 \pm 21$ & $39 \pm 14$ & $<0.001$ \\
\hline PAPdiastolic (mm Hg) & $28 \pm 17$ & $11 \pm 5$ & 0.003 \\
\hline PAPmean (mm Hg) & $45 \pm 12$ & $25 \pm 6$ & $<0.001$ \\
\hline PVR(dyne s/cm5) & $661 \pm 338$ & n.m. & - \\
\hline TPR (dyne s/cm5) & $870 \pm 391$ & $406 \pm 171$ & 0.001 \\
\hline Cardiac output (I/min) & $4.2 \pm 1.1$ & $4.8 \pm 0.8$ & ns \\
\hline BPsystolic (mm Hg) & $120 \pm 39$ & n.m. & - \\
\hline BPsystolic (mm Hg) & $78 \pm 8$ & n.m. & - \\
\hline PCWP (mm Hg) & $7 \pm 5$ & n.m. & - \\
\hline RAP (mm Hg) & $10 \pm 3$ & n.m. & - \\
\hline
\end{tabular}

The 'n.m." indicates that the value is not measured on the intensive care unit (ICU). PAP = pulmonary artery pressure; $\mathrm{PVR}=$ pulmonary vascular resistance; $\mathrm{RAP}=$ right atrial pressure; other abbreviations as in Table 1

LV and RV free walls and the septum before and after PEA in one patient. Pre PEA, the LV and RV start simultaneously, but the RV reaches its peak later than the LV. Post operatively, the RV peak is not later than the LV peak. In the patients before PEA, RV free wall peak circumferential shortening was decreased (pre PEA, $-13 \pm 3 \%$ vs. control, $-18 \pm 2 \%: P<0.001)$, while peak circumferential shortening of LV free wall did not differ as compared with the healthy controls. After PEA, $\mathrm{RV}$ peak circumferential shortening increased to normal values. (Figure 2).

\section{Timing parameters}

The results of the timing parameters pre-and post PEA are shown in Figure 3 and Table 4. Before PEA, the time to peak RV strain $\left(T_{\text {peak }} \mathrm{RV}\right)$ was significantly longer compared with $T_{\text {peak }} \mathrm{LV}$, resulting in a L-R delay in peak strain. Postoperatively, $T_{\text {peak }} R V$ was significantly reduced; whereas $T_{\text {peak }} \mathrm{LV}$ did not change. Consequently, the L-R delay decreased from $97 \pm 49 \mathrm{~ms}$ to values not different from the controls i.e., they reached normal values: $-4 \pm 51 \mathrm{~ms}(P<0.001)$. In addition the Septal to RV delay also normalized post PEA. Individual RV segmental data of the peak strains are presented in Table 5.

\section{Correlation and linear regression analysis}

All variables satisfied the condition of normal distribution. The results of correlation and linear regression analysis are shown in Figure 4. Several recovery parameters were significantly associated with the reduction in L-R delay: increase in LV stroke volume $(\mathrm{r}=0.75, P<0.001)$, increase in normalized LV peak filling rate $(\mathrm{r}=0.64, P<$ $0.001)$, and increase in 6 minute walking distance $(\mathrm{r}=$ $0.67, P<0.001)$. In contrast, there was no significant correlation between the decrease in systolic pulmonary artery pressure and the decrease in L-R delay $(r=0.53, P=0.07)$. Also there was no relation between the decrease in RVradius and decrease in $\mathrm{L}-\mathrm{R}$ delay $(\mathrm{r}=0.37, P=0.21)$, and no relation between the increase in end-systolic wall thickness and decrease in $\mathrm{L}-\mathrm{R}$ delay $(\mathrm{r}=0.19, \mathrm{P}=0.53)$.

\section{RV end-systolic wall stress}

After PEA, the estimated RV end-systolic wall stress decreased significantly from $15.2 \pm 6.4 \mathrm{kPa}$ to $5.7 \pm 3.4$ $\mathrm{kPa}(P<0.001)$, which was not different from the normal reference values of $5.3 \pm 1.39 \mathrm{kPa}(P=0.78)$ (Figure $5 \mathrm{a})$. In addition the RV end-systolic free wall thickness increased significantly after PEA $(0.98 \pm 0.17 \mathrm{~cm}$ vs. $1.21 . \pm 0.38 \mathrm{~cm}$, $P=0.01$ ). Furthermore, as shown in Figure $5 \mathrm{~b}$, the change in L-R delay correlated significantly with the reduction in RV end-systolic wall stress $(r=0.69, \mathrm{P}=0.007)$.

\section{Discussion}

The major findings of the present study are: (1) after PEA, both the L-R delay in peak strains and estimates of

Table 3 Results of CMR volumetric parameters before and after PEA

\begin{tabular}{|c|c|c|c|c|}
\hline CMR variables & Pre PEA & Post PEA & Mean Change (Postop to Preop) & p-Value \\
\hline \multicolumn{5}{|l|}{ Left Ventricle } \\
\hline end diastolic volume (ml) & $98 \pm 15$ & $111 \pm 19$ & $13 \pm 11$ & $<0.001$ \\
\hline end systolic volume (ml) & $28 \pm 47$ & $31 \pm 46$ & $1 \pm 15$ & 0.89 \\
\hline stroke volume $(\mathrm{ml})$ & $59 \pm 13$ & $72 \pm 10$ & $13 \pm 11$ & $<0.001$ \\
\hline ejection fraction (\%) & $62 \pm 13$ & $67 \pm 5$ & $5 \pm 15$ & 0.24 \\
\hline $\operatorname{PFR}(\mathrm{ml} / \mathrm{s})$ & $309 \pm 89$ & $474 \pm 172$ & $165 \pm 150$ & 0.002 \\
\hline PFR/end diastolic volume $\left(\mathrm{s}^{-1}\right)$ & $2.9 \pm 0.8$ & $4.2 \pm 1.3$ & $1.3 \pm 1.1$ & 0.003 \\
\hline \multicolumn{5}{|l|}{ Right Ventricle } \\
\hline end diastolic volume (ml) & $173 \pm 38$ & $125 \pm 18$ & $-47 \pm 41$ & 0.001 \\
\hline end systolic volume (ml) & $107 \pm 34$ & $46 \pm 16$ & $-61 \pm 31$ & $<0.001$ \\
\hline stroke volume $(\mathrm{ml})$ & $65 \pm 19$ & $78 \pm 14$ & $13 \pm 22$ & 0.07 \\
\hline ejection fraction (\%) & $39 \pm 12$ & $63 \pm 10$ & $24 \pm 14$ & $<0.001$ \\
\hline Mass (g) & $75 \pm 19$ & $51 \pm 14$ & $-24 \pm 13$ & $<0.001$ \\
\hline
\end{tabular}



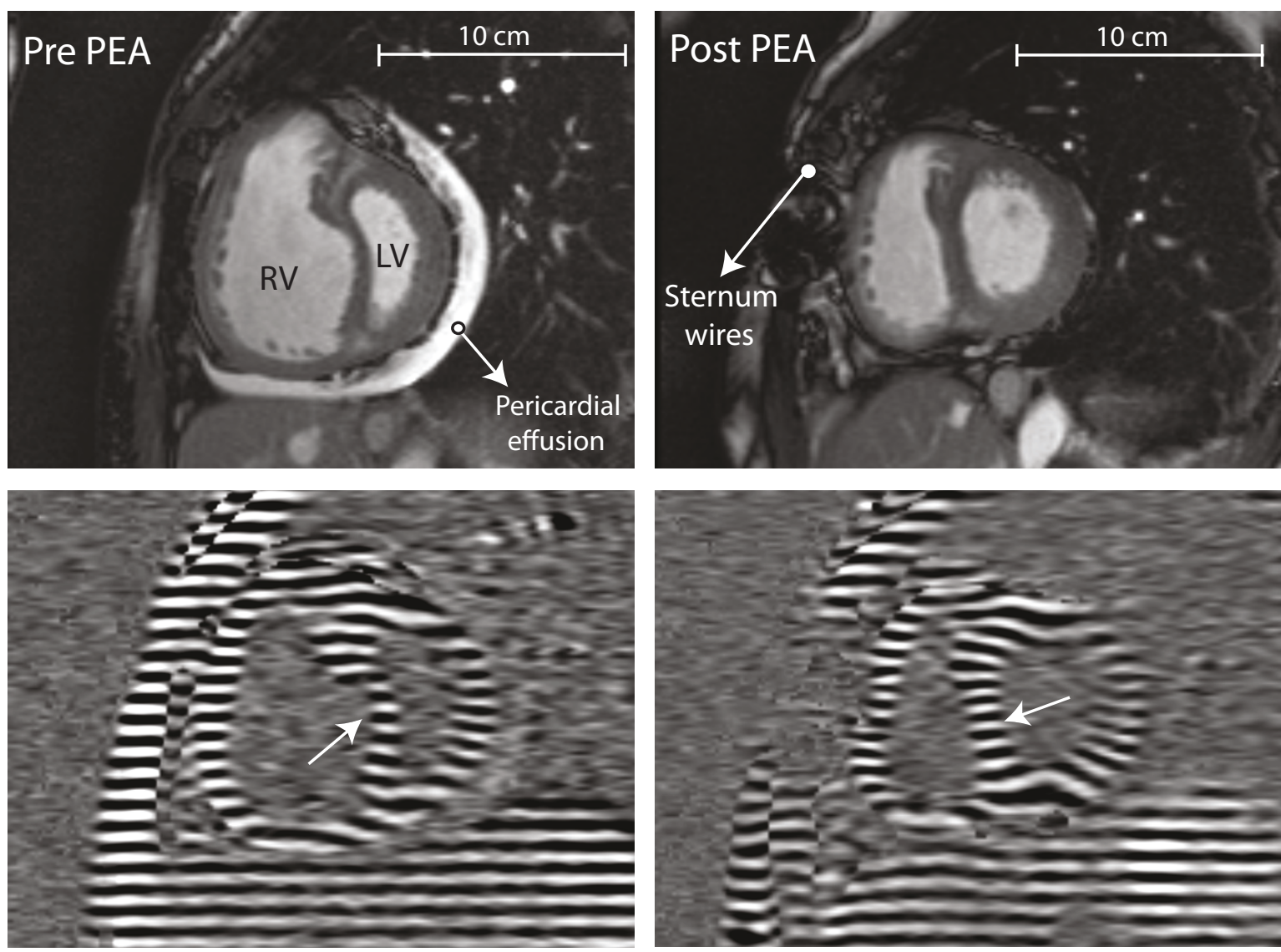

Figure 1 Short-axis images (top panels) and short-axis tagged images (bottom panels), at the time of peak right ventricular (RV) shortening in a patient with chronic thromboembolic pulmonary hypertension before and after pulmonary endarterectomy (PEA) Leftward ventricular septal bowing, as present before PEA, recovers 6 months after PEA (white arrows). CMR = cardiovascular magnetic resonance. $\mathrm{RV}$ = right ventricle, $\mathrm{LV}=$ left ventricle.

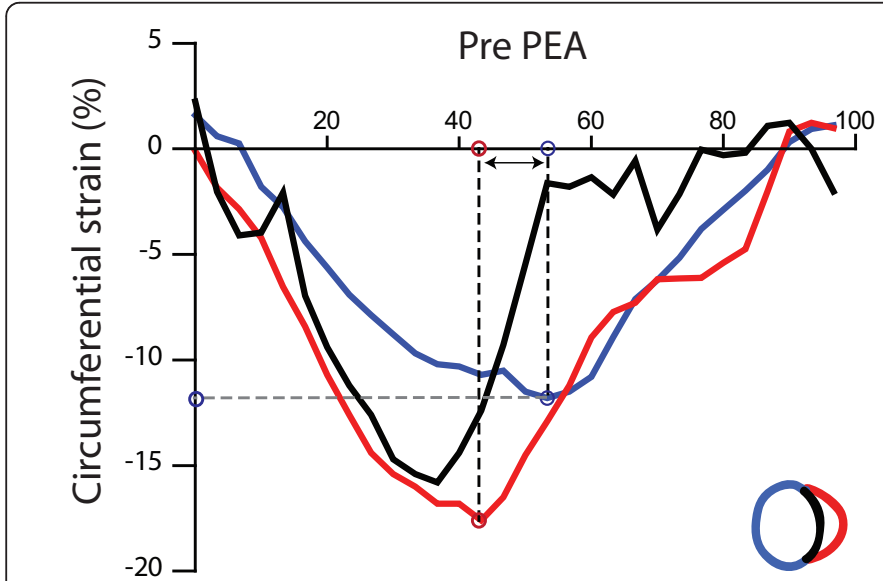

Relative time over the cardiac cycle (\%)

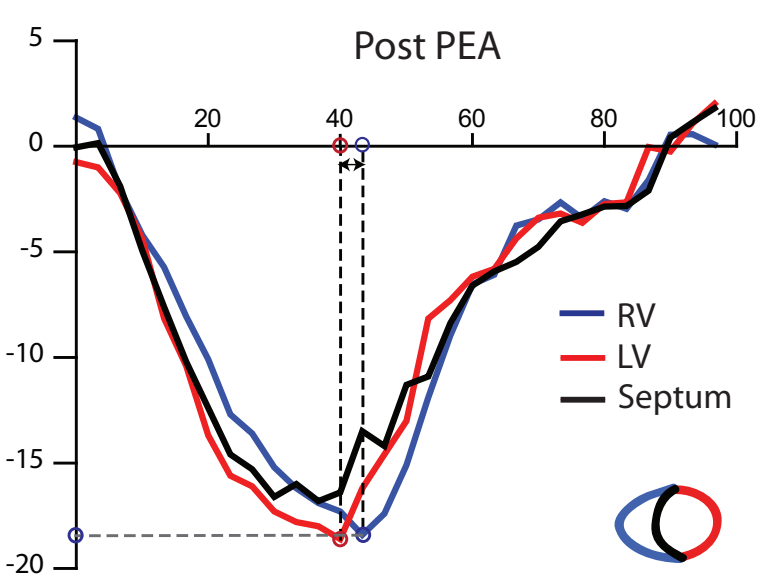

Relative time over the cardiac cycle (\%)

Figure 2 Circumferential strain curves over time after the electrocardiographic R-wave for the left ventricular (LV) and right ventricular (RV) free walls and the septum for 1 patient pre (left) and post (right) PEA. Pre PEA, the LV, RV, and septum start

simultaneously with shortening (negative strain), but the RV reaches its peak later than the LV and the RV peak strain is lower. Post PEA, the L-R synchrony and RV peak strain have recovered. 


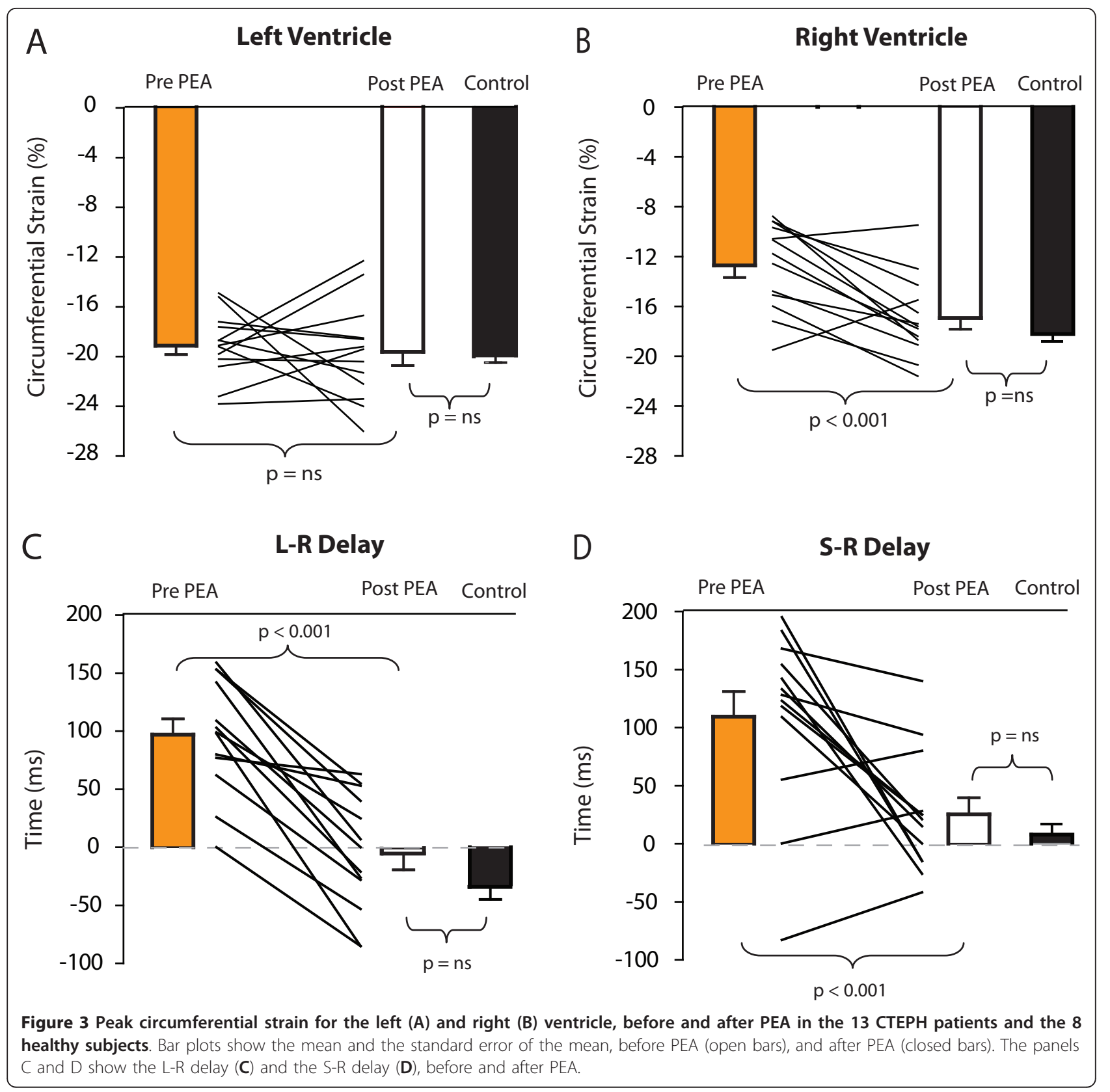

end-systolic wall stress reverse to normal values; and (2) the change in L-R delay is predominantly associated with the change in RV end-systolic wall stress.

Our findings of a decrease in L-R dyssynchrony after unloading the RV, agree with the previous observations by Lurz et al [12] in patients where an RV-pulmonary artery conduit obstruction was relieved. Similar to our study, they reported that the reduction in RV wall stress correlated with the reduction in L-R delay. We showed that this also applies for patients with pulmonary hypertension and in addition we proved that the synchronyrecovery is mainly explained by the combined effect of reduction in PAP pressure, end-systolic radius and increased wall thickness. Since we also included healthy subjects, we were able to prove that RV peak strain, wall stress, as well as L-R synchrony reversed to normal values (Figure 3 and 5). This implies that the failing RV is capable of functional recovery after an intervention that reduces RV wall stress.

In this study, we performed the CMR measurements at least six months post-operatively, since previous reports showed that unloading the ventricle results in morphological and functional improvement over a period of at least 3 months $[17,18]$. In addition, Reesink et 
Table 4 CMR Strain and Timing Parameters before and after PEA

\begin{tabular}{ccccc}
\hline Strain and timing & Pre PEA & Post PEA & Mean Change (Postop to Preop) & p-Value \\
\hline LV peak strain (\%) & $-19 \pm 3$ & $-20 \pm 4$ & $-0.5 \pm 5$ & $-4 \pm 3$ \\
RV peak strain (\%) & $-13 \pm 3$ & $-17 \pm 3$ & $-2 \pm 3$ & 0.001 \\
SP peak strain (\%) & $-14 \pm 3$ & $-16 \pm 4$ & $17 \pm 134$ & 0.09 \\
RR (ms) & $823 \pm 70$ & $840 \pm 90$ & - & -70 \\
$T_{\max }$ LVSB (ms) & $397 \pm 77$ & Not observed & $-53 \pm 80$ & 0.64 \\
$T_{\text {peak }}$ RV (ms) & $405 \pm 61$ & $352 \pm 67$ & $46 \pm 80$ & 0.09 \\
$T_{\text {peak }} L$ (ms) & $310 \pm 46$ & $356 \pm 45$ & $-23 \pm 82$ & 0.33 \\
$T_{\text {peak }}$ SP (ms) & $296 \pm 43$ & $320 \pm 58$ & $-101 \pm 49$ & $<0.001$ \\
LV to RV delay in Tpeak (ms) & $97 \pm 49$ & $-4 \pm 51$ & $-85 \pm 84$ & 0.004 \\
SP to RV delay in Tpeak (ms) & $110 \pm 78$ & $25 \pm 51$ & \\
\hline
\end{tabular}

$\mathrm{LV}=$ left ventricular; $\mathrm{LVSB}=$ leftward septal bowing; $\mathrm{RV}$ = right ventricular; $\mathrm{RR}=\mathrm{R}$ to $\mathrm{R}$ interval; $\mathrm{SP}=$ septum; $\mathrm{T}_{\text {peak }}=$ Time to peak; $\mathrm{T}_{\max }=$ Time of maximal $\mathrm{LVSB}$

al [19] showed, by performing CMR after at least 4 months, that an almost complete reverse RV remodelling had taken place. However for the invasive pressures, we used the direct post-operative pressure measurements for the calculation of wall stress. The combination of post-operative CMR after 6 months and the postoperative pressure values is a limitation in this study, since the CMR derived values reflect a reverseremodeled state whereas the post-PEA hemodynamics do not. Nevertheless, previous reports indicate that the pulmonary artery pressure remains stable during followup after PEA [20,21].

\section{Experimental Data}

Our results agree with data on cardiac muscle. Brutsaert et al [22] and others [23] investigated the relationship between load and contraction duration by showing that an acute higher afterload imposed on isolated muscles increased the duration of contraction. Recently,

Table 5 Individual segmental data of peak strain (in \% circumferential shortening) for RV free wall segments anterior, mid and posterior

\begin{tabular}{|c|c|c|c|c|c|c|c|c|c|}
\hline \multirow[t]{2}{*}{ Patient } & \multicolumn{3}{|c|}{$\begin{array}{l}\text { RV anterior } \\
\text { segment }\end{array}$} & \multicolumn{3}{|c|}{ RV mid segment } & \multicolumn{3}{|c|}{$\begin{array}{l}\text { RV posterior } \\
\text { segment }\end{array}$} \\
\hline & Pre & Post & Delta & Pre & Post & Delta & Pre & Post & Delta \\
\hline 1 & -5.7 & -13.1 & -7.4 & -8.3 & -13.3 & -5.0 & 12.7 & -13.4 & -0.7 \\
\hline 2 & -11.0 & -10.2 & 0.8 & -10.1 & -10.1 & 0.0 & -13.2 & -8.8 & 4.4 \\
\hline 3 & -4.7 & -16.5 & -11.7 & -9.7 & -11.0 & -1.3 & -11.1 & -13.9 & -2.8 \\
\hline 4 & -6.6 & -18.9 & -12.3 & -8.5 & -18.7 & -10.2 & -4.4 & -17.0 & -12.6 \\
\hline 5 & -15.4 & -26.0 & -10.6 & -12.2 & -21.0 & -8.8 & -12.4 & -18.9 & -6.5 \\
\hline 6 & -15.9 & -19.1 & -3.2 & -11.8 & -18.0 & -6.2 & -13.0 & -19.9 & -6.9 \\
\hline 7 & -16.2 & -17.8 & -1.6 & -13.8 & -17.4 & -3.6 & -16.4 & -16.6 & -0.2 \\
\hline 8 & -12.2 & -17.8 & -5.6 & -11.1 & -20.6 & -9.5 & -12.1 & -16.8 & -4.7 \\
\hline 9 & -11.3 & -17.3 & -6.0 & -12.6 & -18.2 & -5.6 & -10.7 & -13.7 & -3.0 \\
\hline 10 & -10.1 & -15.2 & -5.1 & -10.0 & -17.2 & -7.2 & -11.5 & -18.0 & -6.5 \\
\hline 11 & -11.3 & -19.3 & -8.0 & -10.9 & -21.9 & -11 & -17.0 & -21.4 & -4.4 \\
\hline 12 & -11.0 & -15.4 & -4.4 & -8.6 & -15.3 & -6.7 & -9.8 & -13.2 & -3.4 \\
\hline 13 & -18.3 & -15.1 & 3.2 & -18.8 & -14.9 & 3.9 & -21.4 & -16.3 & 5.1 \\
\hline
\end{tabular}
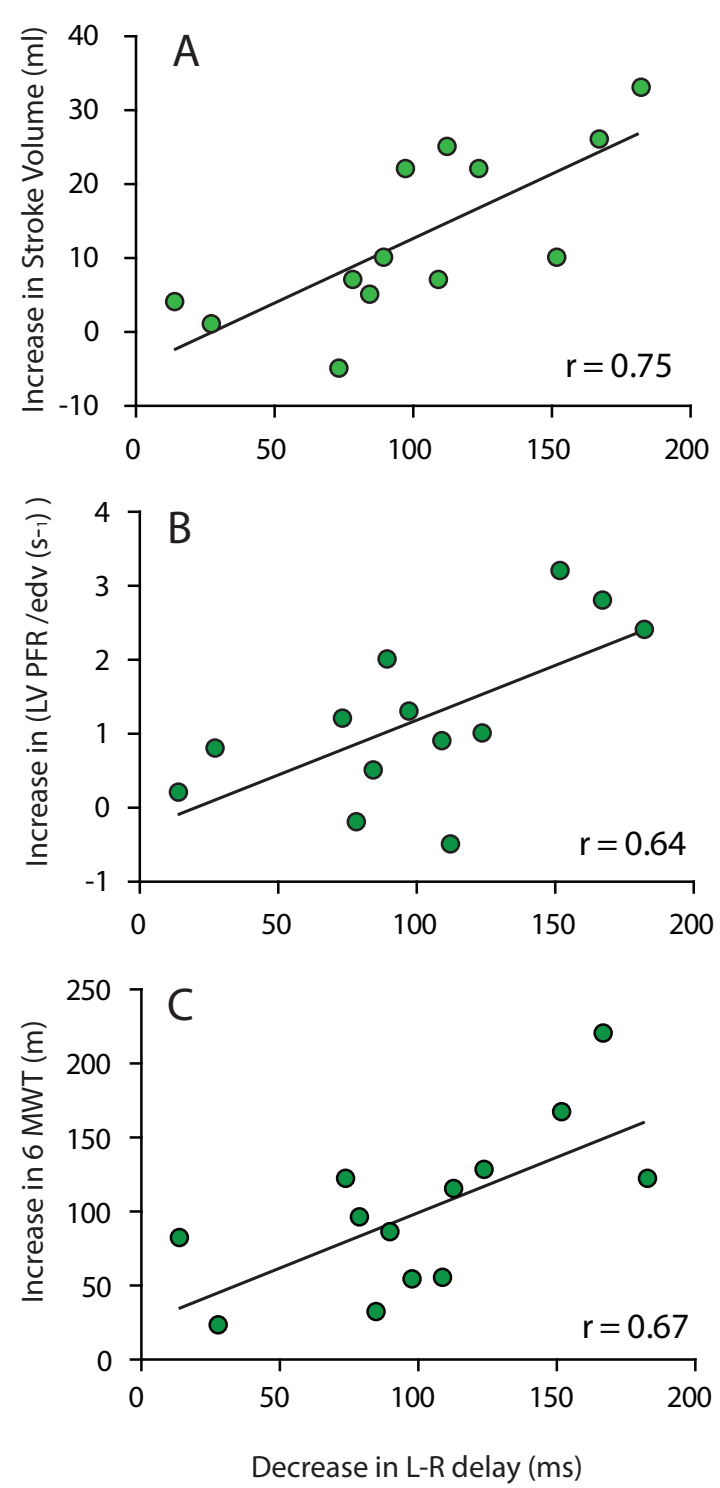

Figure 4 Decrease in L-R delay versus (A) Increase in stroke volume; $(B)$ increase in left ventricular peak filling rate (LV PFR) and (C) increase in six minute walking test. 


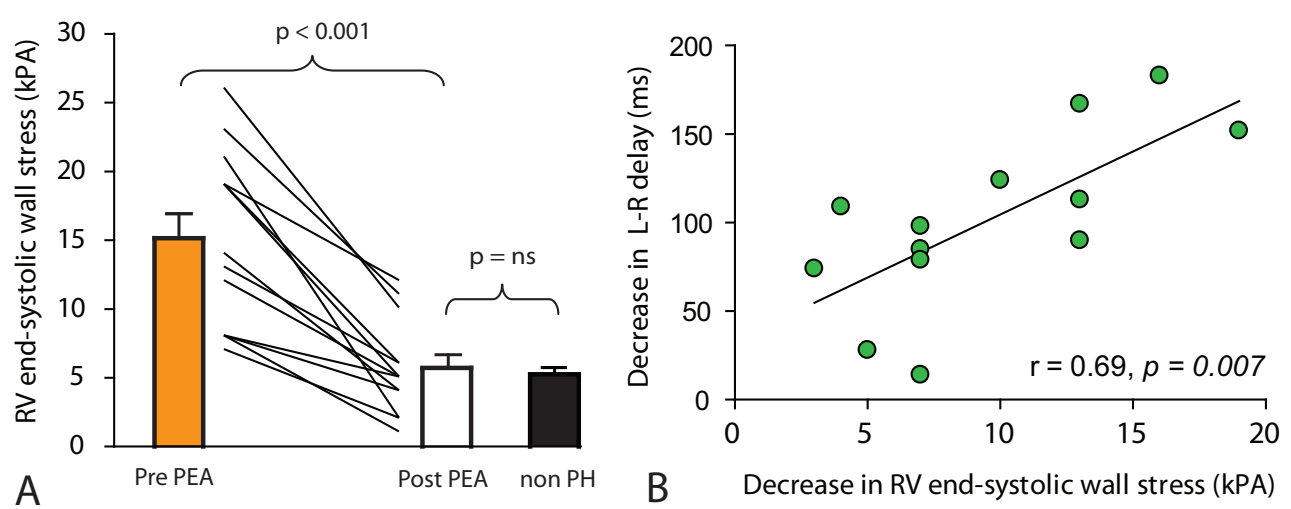

Figure 5 RV end-systolic wall stress (A) before and after PEA in the 13 CTEPH patients and the 8 patients with normal right-sided pressures. Bar plots show the mean and the standard error of the mean, before PEA (open bars), and after PEA (closed bars). (B) Linear regression between the decrease in left-to-right $(L-R)$ delay in time to peak of circumferential shortening as dependent variable and the decrease in right ventricular (RV) end-systolic wall stress.

Handoko et al [11] used an isolated langendorff-perfused heart from a chronic $\mathrm{PH}$ rat model and showed that ventricular dyssynchrony in peak pressure was induced by increasing RV volume and pressure, using an inflatable ventricular balloon. Thus the increase of myocardial wall stress leads to prolonged contraction duration, in experimental conditions as well.

\section{End-systolic wall stress in Pulmonary Hypertension}

The finding that end-systolic wall stress is increased in CTEPH, is in accordance with earlier reports on pulmonary hypertension $[24,25]$. The increased wall stress does not only affect RV contraction duration, but also negatively affects myocardial perfusion [26] and subsequent glucose metabolism [25], and increases oxygen demand [27] Furthermore, Grossman et al [28] showed that increased wall stress induced dilatation, which in turn leads to further increase in wall stress and thereby a vicious circle of positive feedback is maintained.

Lowering end-systolic wall stress can be achieved by both a reduction of RV pressure and by an improvement in RV adaptation through concentric hypertrophy [29]. The relevance of this adaptation is manifest in patients with $\mathrm{PH}$ due to congenital heart disease: In these patients, the RV is more capable to cope with the increased afterload, probably because the RV has had more time to adapt by developing compensatory hypertrophy. This underscores the relevance of hypertrophy for lowering wall stress, and thereby for reducing $L-R$ dyssynchrony in RV pressure overload.

\section{Limitation}

The number of patients in this study was small. This is a consequence of the very invasive surgical PEA procedure, which can only be applied in a small subset of CTEPH patients. However, all statistical analyses were performed within patient, comparing the data before and after surgery by paired samples t-testing. This made it possible to obtain significant results in a small number.

Furthermore, a simplifying assumption is the description of the RV end-systolic volume by a spherical configuration, which is used in the calculation of RV wall stress for both the patients and the control subjects.

\section{Conclusions}

In CTEPH patients, the L-R dyssynchrony in peak strain recovers to normal values after PEA. The RV end-systolic wall stress plays a key role in this recovery, reflecting a complex interplay of pulmonary artery pressure, $\mathrm{RV}$ radius and wall thickness.

Funding and support

Anton Vonk-Noordegraaf was supported by Netherlands Organisation for Scientific Research (NWO)-VIDI.

\section{Author details}

${ }^{1}$ Department of Pulmonary Diseases, University of Amsterdam, Amsterdam, The Netherlands. ${ }^{2}$ Department of Physics and Medical Technology, University of Amsterdam, Amsterdam, The Netherlands. ${ }^{3}$ Department of Physiology, Institute for Cardiovascular Research, VU University Medical Center,

Amsterdam, the Netherlands. ${ }^{4}$ Department of Pulmonary Diseases, University of Amsterdam, Amsterdam, The Netherlands. ${ }^{5}$ Department of Cardiothoracic Surgery of the Academic Medical Center, University of Amsterdam, Amsterdam, The Netherlands. ${ }^{6}$ Department of Respiratory Medicine, Onze Lieve Vrouwe Gasthuis, Amsterdam, the Netherlands.

\section{Authors' contributions}

GM is responsible for conception and design of this study, data acquisition, analysis and interpretation of the results and drafting of the manuscript; AV is responsible for conception and design of this study and revising of the manuscript; TK carried out data acquisition, analysis and interpretation of the results. SS carried out data analysis; JK performed the surgical procedure and revising of the manuscript; $\mathrm{PB}$ revising of the manuscript; NS carried out data acquisition; JB carried out data acquisition, analysis and interpretation 
of the results; NW: is responsible for conception and design of this study; JM is responsible for conception and design of this study, interpretation of the results and drafting of the manuscript.

\section{Competing interests}

The authors declare that they have no competing interests.

Received: 24 June 2011 Accepted: 12 January 2012

Published: 12 January 2012

\section{References}

1. Roeleveld RJ, Marcus JT, Faes TJ, Gan TJ, Boonstra A, Postmus PE, VonkNoordegraaf A: Interventricular septal configuration at $\mathrm{mr}$ imaging and pulmonary arterial pressure in pulmonary hypertension. Radiology 2005 234(3):710-717.

2. Kingma I, Tyberg JV, Smith ER: Effects of diastolic transseptal pressure gradient on ventricular septal position and motion. Circulation 1983, 68(6):1304-1314

3. Tanaka H, Tei C, Nakao S, Tahara M, Sakurai S, Kashima T, Kanehisa T: Diastolic bulging of the interventricular septum toward the left ventricle. An echocardiographic manifestation of negative interventricular pressure gradient between left and right ventricles during diastole. Circulation 1980, 62(3):558-563.

4. Dohi K, Onishi K, Gorcsan J, López-Candales A, Takamura T, Ota S, Yamada N, Ito M: Role of radial strain and displacement imaging to quantify wall motion dyssynchrony in patients with left ventricular mechanical dyssynchrony and chronic right ventricular pressure overload. Am J Cardiol 2008, 101(8):1206-1212.

5. Marcus JT, Gan CT, Zwanenburg JJ, Boonstra A, Allaart CP, Götte MJ, VonkNoordegraaf A: Interventricular mechanical dyssynchrony in pulmonary arterial hypertension: left-to-right delay in peak shortening is related to right ventricular overload and left ventricular underfilling. J Am Coll Cardiol 2008, 51(7):750-757.

6. Lopez-Candales A, Dohi K, Rajagopalan N, Suffoletto M, Murali S, Gorcsan J, Edelman K: Right ventricular dyssynchrony in patients with pulmonary hypertension is associated with disease severity and functional class. Cardiovasc Ultrasound 2005, 3:23.

7. Kalogeropoulos AP, Georgiopoulou W, Howell S, Pernetz MA, Fisher MR, Lerakis S, Martin RP: Evaluation of right intraventricular dyssynchrony by two-dimensional strain echocardiography in patients with pulmonary arterial hypertension. J Am Soc Echocardiogr 2008, 21(9):1028-1034

8. Beyar R: Heart inefficiency in pulmonary hypertension: a double jeopardy. J Am Coll Cardiol 2008, 51(7):758-759.

9. Gan CT, Lankhaar JW, Marcus JT, Westerhof N, Marques KM, Bronzwaer JG Boonstra A, Postmus PE, Vonk-Noordegraaf A: Impaired left ventricular filling due to right-to-left ventricular interaction in patients with pulmonary arterial hypertension. Am J Physiol Heart Circ Physiol 2006, 290(4):H1528-1533.

10. Stojnic BB, Brecker SJ, Xiao HB, Helmy SM, Mbaissouroum M, Gibson DG: Left ventricular filling characteristics in pulmonary hypertension: a new mode of ventricular interaction. Br Heart J 1992, 68(1):16-20.

11. Handoko ML, Lamberts RR, Redout EM, de Man FS, Boer C, Simonides WS, Paulus WJ, Westerhof N, Allaart CP, Vonk-Noordegraaf A: Right ventricular pacing improves right heart function in experimental pulmonary arterial hypertension: a study in the isolated heart. Am J Physiol Heart Circ Physiol 2009, 297(5):H1752-1759.

12. Lurz P, Puranik R, Nordmeyer J, Muthurangu V, Hansen MS, Schievano S, Marek J, Bonhoeffer P, Taylor AM: Improvement in left ventricular filling properties after relief of right ventricle to pulmonary artery conduit obstruction: contribution of septal motion and interventricular mechanical delay. Eur Heart J 2009, 30(18):2266-2274.

13. Auger WR, Fedullo PF, Moser KM, Buchbinder M, Peterson KL: Chronic major-vessel thromboembolic pulmonary artery obstruction: appearance at angiography. Radiology 1992, 182(2):393-398.

14. Osman NF, Kerwin WS, McVeigh ER, Prince JL: Cardiac motion tracking using CINE harmonic phase (HARP) magnetic resonance imaging. Magn Reson Med 1999, 42(6):1048-1060

15. Zwanenburg JJ, Gotte MJ, Kuijer JP, Heethaar RM, van Rossum AC, Marcus JT: Timing of cardiac contraction in humans mapped by hightemporal-resolution MRI tagging: early onset and late peak of shortening in lateral wall. Am J Physiol Heart Circ Physiol 2004, 286(5) H1872-1880

16. Norton JM: Toward consistent definitions for preload and afterload. Adv Physiol Educ 2001, 25(1-4):53-61.

17. Cihak R, Kolar F, Pelouch V, Prochazka J, Ostadal B, Widimsky J: Functional changes in the right and left ventricle during development of cardiac hypertrophy and after its regression. Cardiovasc Res 1992, 26(9):845-850.

18. D'Armini AM, Zanotti G, Ghio S, Magrini G, Pozzi M, Scelsi L, Meloni G, Klersy $C$, Viganò M: Reverse right ventricular remodeling after pulmonary endarterectomy. J Thorac Cardiovasc Surg 2007, 133(1):162-168.

19. Reesink HJ, Marcus JT, Jamieson S, Kloek JJ, Vonk Noordegraaf A, Bresser P: Reverse right ventricular remodeling after pulmonary endarterectomy in patients with chronic thromboembolic pulmonary hypertension: utility of magnetic resonance imaging to demonstrate restoration of the right ventricle. J Thorac Cardiovasc Surg 2007, 133(1):58-64.

20. Giusca S, Dambrauskaite V, Scheurwegs C, D'hooge J, Claus P, Herbots L, Magro M, Rademakers F, Meyns B, Delcroix M, Voigt JU: Deformation imaging describes right ventricular function better than longitudinal displacement of the tricuspid ring. Heart 2010, 96(4):281-288.

21. Freed DH, Thomson BM, Tsui SS, Dunning JJ, Sheares KK, Pepke-Zaba J, Jenkins DP: Functional and haemodynamic outcome 1 year after pulmonary thromboendarterectomy. Eur I Cardiothorac Surg 2008, 34(3):525-529, discussion 529-530.

22. Brutsaert DL, Rademakers FE, Sys SU: Triple control of relaxation: implications in cardiac disease. Circulation 1984, 69(1):190-196.

23. van Heuningen R, Rijnsburger WH, ter Keurs HE: Sarcomere length control in striated muscle. Am J Physiol 1982, 242(3):H411-420,

24. Quaife RA, Chen MY, Lynch D, Badesch DB, Groves BM, Wolfel E, Robertson AD, Bristow MR, Voelkel NF: Importance of right ventricular end-systolic regional wall stress in idiopathic pulmonary arterial hypertension: a new method for estimation of right ventricular wall stress. Eur J Med Res 2006, 11(5):214-220.

25. Oikawa M, Kagaya Y, Otani H, Sakuma M, Demachi J, Suzuki J, Takahashi T, Nawata J, Ido T, Watanabe J, Shirato K: Increased [18F]fluorodeoxyglucose accumulation in right ventricular free wall in patients with pulmonary hypertension and the effect of epoprostenol. J Am Coll Cardiol 2005, 45(11):1849-1855.

26. Gomez A, Bialostozky D, Zajarias A, Santos E, Palomar A, Martínez ML, Sandoval $\mathrm{J}$ : Right ventricular ischemia in patients with primary pulmonary hypertension. J Am Coll Cardiol 2001, 38(4):1137-1142.

27. Westerhof N, Boer C, Lamberts RR, Sipkema P: Cross-talk between cardiac muscle and coronary vasculature. Physiol Rev 2006, 86(4):1263-1308.

28. Grossman W, Jones D, McLaurin LP: Wall stress and patterns of hypertrophy in the human left ventricle. J Clin Invest 1975, 56(1):56-64.

29. Vonk Noordegraaf A, Westerhof N: Right ventricular ejection fraction and NT-proBNP are both indicators of wall stress in pulmonary hypertension. Eur Respir J 2007, 29(4):622-623.

doi:10.1186/1532-429X-14-5

Cite this article as: Mauritz et al:: Pulmonary endarterectomy normalizes interventricular dyssynchrony and right ventricular systolic wall stress. Journal of Cardiovascular Magnetic Resonance 2012 14:5.

\section{Submit your next manuscript to BioMed Central and take full advantage of:}

- Convenient online submission

- Thorough peer review

- No space constraints or color figure charges

- Immediate publication on acceptance

- Inclusion in PubMed, CAS, Scopus and Google Scholar

- Research which is freely available for redistribution 